\title{
THE IN-SITU GENERATION OF SILICA REINFORCEMENT IN MODIFIED POLYDIMETHYLSILOXANE ELASTOMERS ${ }^{+}$
}

S. PRABAKAR*, S. E. BATES**, E. P. BLACK**, T. A. ULIBARRI**,

D, W. SCHAEFER**, G. BEAUCAGE** AND R. A. ASSINK*,**

*Advanced Materials Laboratory, University of New Mexico, Albuquerque, NM 87106,

**Sandia National Laboratories, Albuquerque, NM 87185-1407.

\section{ABSTRACT}

The structure and properties of a series of modified polydimethylsiloxane (PDMS) elastomers reinforced by in situ generated silica particles were investigated. The PDMS elastomer was modified by systematically varying the molecular weight between reactive groups incorporated into the backbone. Tetraethoxysilane (TEOS) and partial hydrolyzate of TEOS were used to generate silica particles. The chemistry and phase structure of the materials were investigated by ${ }^{29} \mathrm{Si}$ magic angle spinning nuclear magnetic resonance (NMR) spectroscopy and swelling experiments.

\section{INTRODUCTION}

The in-situ generation of silica particles by the sol-gel method provides an alternative route to prepare reinforced polydimethylsiloxane polymers $[1,2]$. Although the chemistry of the individual components have been the subject of numerous investigations, the interaction of the two phases has only recently been the subject of investigation [3]. We have begun a systematic study of the in situ growth of the silica reinforcement phase within the PDMS elastomer. Reactive functional groups were incorporated into the elastomer backbone in order to modulate the degree of interaction between the matrix and filler phases:

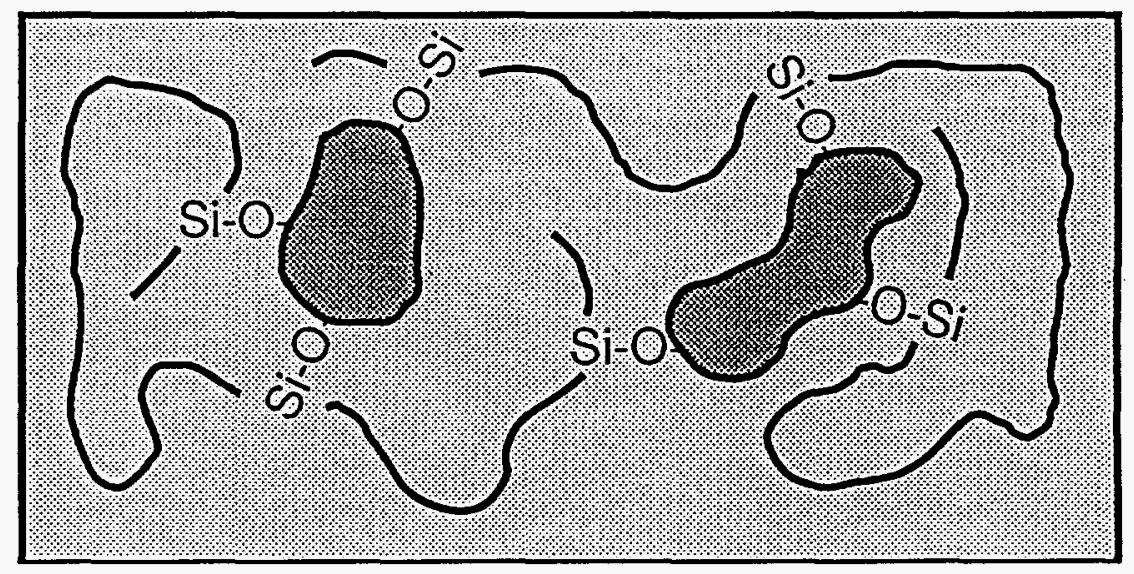

The local chemical structures and extents of reaction of the materials were measured by solid state ${ }^{29} \mathrm{Si} \mathrm{NMR} \mathrm{spectroscopy.} \mathrm{Solubility} \mathrm{and} \mathrm{swelling} \mathrm{experiments} \mathrm{were} \mathrm{use} \mathrm{to} \mathrm{determine} \mathrm{the} \mathrm{extent} \mathrm{to}$ which the two phases were chemically coupled, while ${ }^{29} \mathrm{Si}$ NMR relaxation times were used to determine the extent to which the two phases were physically coupled.

\section{EXPERIMENTAL}

Preparation of $\left(\mathrm{Me}_{2} \mathrm{SiO}\right)_{x}(\mathrm{MeOMeSiO})_{y}$ Copolymers

A mixture of dimethylsiloxanes (DC 2-0409), linear methylhydrogen siloxanes (DC-1107) and hexamethyldisiloxane were used to prepare $\mathrm{Me}_{2} \mathrm{SiO} / \mathrm{MeHSiO}$ copolymers capped with + This work supported by the United States Department of Energy under contract DE-AC04-94AL8500.

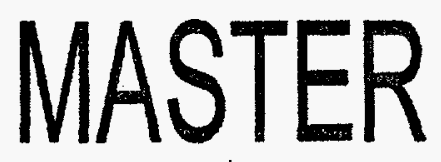




\section{DISCLAIMER}

Portions of this document may be illegible in electronic image products. Images are produced from the best available original document. 
trimethylsilyl. Trifluoromethanesulfonic acid ( 0.1 weight \%) was added to the three component system and the solution was heated to $70^{\circ} \mathrm{C}$ for 4 hours. The resulting reaction mixture was neutralized by the addition of a ten-fold excess of sodium bicarbonate. The copolymers were then filtered and used without further purification. To methoxylate the silicon hydride moiety, the $\left(\mathrm{Me}_{2} \mathrm{SiO}\right)_{\mathrm{x}}(\mathrm{MeHSiO})_{\mathrm{y}}$ copolymer, anhydrous methanol, and $\mathrm{N}, \mathrm{N}$-diethylhydroxylamine (1 weight \%) were combined and stirred in a sealed vessel until complete substitution was achieved. Completion of the reaction was indicated by the absence of the Si-H band at $2150 \mathrm{~cm}^{-1}$ in the FTIR. The resulting copolymers were used without any further purification.

\section{Preparation of Tetraethoxysilane Partial Hydrolyzate (TEOS-PH)}

Tetraethoxysilane partial hydrolyzate was prepared by the addition of substoichiometric amounts of deionized water in absolute ethanol to an acidified solution of tetraethoxysilane. After stirring, the acid was neutralized with sodium bicarbonate and volatiles were removed by distillation. The solution was then filtered to remove salts and used without further purification.

\section{Preparation of Elastomers}

The silica-filled elastomeric materials were prepared by mixing the matrix polymer, in the presence of dibutyltin dilaurate catalyst $(0.2$ weight $\%)$, with TEOS or TEOS-PH, in amounts sufficient to both crosslink and fill the matrix to 10 weight \% silica. Samples 2 to $3 \mathrm{~mm}$ thick were allowed to cure in a $60 \%$ relative humidity $\left(R_{H}\right)$ environment for 1 week. The final elastomer compositions are shown in Table 1 where the $x / y$ ratios correspond to the relative values of $x$ and $y$ in the $\left(\mathrm{Me}_{2} \mathrm{SiO}\right)_{x}(\mathrm{MeHSiO})_{y}$ copoolymer.

Table 1: The elastomeric structures, the silica precursors and the degree of polymerization for the filled elastomers.

\begin{tabular}{|c|l|c|l|}
\hline $\begin{array}{c}\text { Copolymer } \\
\mathrm{x} / \mathrm{y}\end{array}$ & Silica Precursor & $\begin{array}{c}\text { Degree of } \\
\text { Polymerization (dp) }\end{array}$ & Copolymer Formula \\
\hline $10 / 1$ & TEOS & 506 & $\mathrm{M}\left[\mathrm{D}_{10} \mathrm{~T}^{\mathrm{OMe}}\right]_{46} \mathrm{M}$ \\
$10 / 1$ & TEOS-PH & 506 & $\mathrm{M}\left[\mathrm{D}_{10} \mathrm{~T}^{\mathrm{OMe}}\right]_{46} \mathrm{M}$ \\
$20 / 1$ & TEOS & 504 & $\mathrm{M}\left[\mathrm{D}_{20} \mathrm{~T}^{\mathrm{OMe}}\right]_{24} \mathrm{M}$ \\
$20 / 1$ & TEOS-PH & 504 & $\mathrm{M}\left[\mathrm{D}_{20} \mathrm{~T}^{\mathrm{OMe}}\right]_{24} \mathrm{M}$ \\
$50 / 1$ & TEOS & 510 & $\mathrm{M}\left[\mathrm{D}_{50} \mathrm{~T}^{\mathrm{OMe}}\right]_{16} \mathrm{M}$ \\
$50 / 1$ & TEOS-PH & 510 & $\mathrm{M}\left[\mathrm{D}_{50} \mathrm{~T}^{\mathrm{OMe}}\right]_{16} \mathrm{M}$ \\
\hline
\end{tabular}

\section{Characterization}

Solid state ${ }^{29} \mathrm{Si}$ NMR spectra were recorded at $39.6 \mathrm{MHz}$ on a Chemagnetics console interfaced to a General Electric 1280 data station described previously [4]. The samples were spun about the magic angle in a $7 \mathrm{~mm}$ ceramic rotor at $2.5 \mathrm{kHz}$. A crosspolarization sequence was used with various crosspolarization times and a pulse delay of $4 \mathrm{~s}$.

Equilibrium swelling measurements were conducted by swelling pre-weighed samples in heptane for 4 days. The excess heptane was removed and the samples were weighed in the 
swollen state. The samples were then allowed to dry and their final weights measured. Using the theory of the Flory [5], the molecular weights between crosslinks and the crosslink density were calculated using the following equations:

$$
\begin{aligned}
& \mathrm{M}_{\mathrm{c}}=\mathrm{V}_{\mathrm{S}} \mathrm{r}_{\mathrm{P}}\left(\mathrm{C}^{1 / 3}-\mathrm{C} / 2\right) /\left[\ln (1-\mathrm{C})+\mathrm{C}+\mathrm{CC}^{2}\right] \\
& \mathrm{r}_{\mathrm{c}}=\mathrm{r}_{\mathrm{P}}(\text { Avogadro's } \#) / \mathrm{M}_{\mathrm{c}} \\
& \mathrm{C}=\mathrm{W}_{0} /\left(\mathrm{r}_{\mathrm{P}} \mathrm{V}_{\infty}\right) \\
& \mathrm{V}_{\infty}=\mathrm{W}_{0} \mathrm{TP}_{\mathrm{P}}+\left(\mathrm{W}_{\infty}-\mathrm{W}_{0}\right) / \mathrm{r}_{\mathrm{S}}
\end{aligned}
$$

where $\mathrm{M}_{\mathrm{c}}=$ Average molecular weight of network chains ( $\mathrm{g} / \mathrm{mole}$ ); $\mathrm{V}_{\mathrm{s}}=$ Molar volume of the solvent $\left(146.6 \mathrm{~cm}^{3} / \mathrm{g}\right.$-mole), $\mathrm{C}=$ Flory-Huggins coefficient (Chi parameter, 0.39$) ; \mathrm{r}_{\mathrm{P}}=$ Polymer density $\left(1.0 \mathrm{~g} / \mathrm{cm}^{3}\right) ; r_{\mathrm{s}}=$ Solvent density $\left(0.684 \mathrm{~g} / \mathrm{cm}^{3} ; r_{c}=\right.$ Crosslink density; $\mathrm{C}=$ Relative concentration (dimensionless); $V_{\infty}=$ Final polymer volume $\left(\mathrm{cm}^{3}\right) ; \mathrm{W}_{0}=$ Initial polymer weight (Since the soluble fraction of many of these materials was high, the weight used as the initial polymer weight was the extracted or final dry weight); $\mathrm{W}_{\infty}=$ swollen polymer weight. The soluble fraction was calculated using the following equation:

$$
\text { Soluble Fraction }=100\left(W_{0}-W_{f}\right) / W_{0}
$$

where $\mathrm{W}_{\mathrm{f}}=$ final dry weight after swelling.

\section{RESULTS AND DISCUSSION}

The solid state ${ }^{29} \mathrm{Si}$ NMR spectrum of the 10/1 TEOS material is shown in Fig 1 . The resonance at $-21.4 \mathrm{ppm}$ corresponds to the $\mathrm{D}$ backbone silicons, the resonances at -56.9 and $65.3 \mathrm{ppm}$ correspond to the $T$ backbone silicons which are functionalized and the resonances at 100.7 and $-108.6 \mathrm{ppm}$ correspond to the Q silicons of the silica filler formed by TEOS. The D backbone silicons are not functionalized so a single resonance is observed. The $\mathrm{T}$ silicons begin as $\mathrm{T}^{2}$ silicons, bonded to two neighboring silicons in the chain, and can only undergo a single condensation reaction to form a $\mathrm{T}^{3}$ silicon. The $\mathrm{Q}$ silicons enter the reaction as $\mathrm{Q}^{0}$ species and undergo reactions to form predominately $\mathrm{Q}^{3}$ and $\mathrm{Q}^{4}$ species.

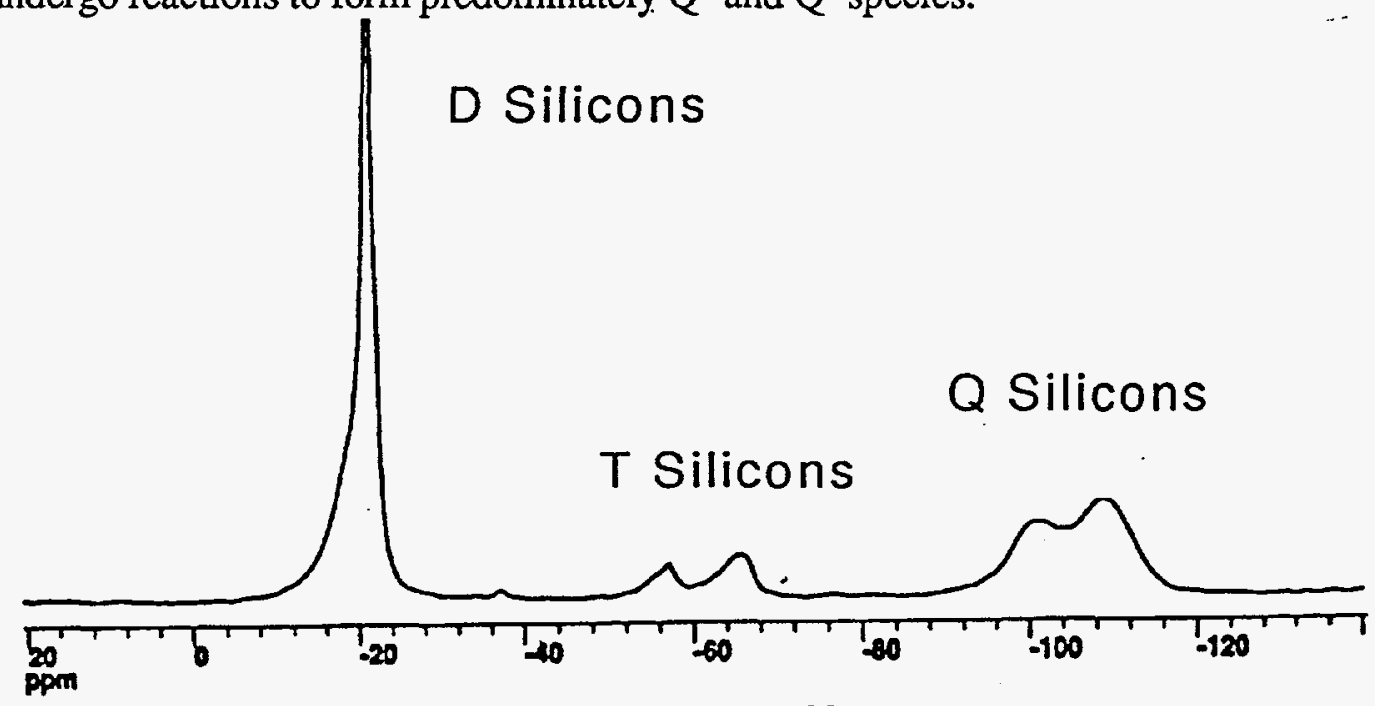

Fig 1. The solid state CPMAS 29 Si NMR spectra of the 10/1 TEOS material showing the $\mathrm{D}, \mathrm{T}$ and $\mathrm{Q}$ silicon species. 
The spectra for each material were recorded as a function of crosspolarization time so that the relative product distributions for each silicon species could be determined. The signal intensities as a function of crosspolarization times are shown in Fig 2 . The experiments were only carried out to $15 \mathrm{~ms}$ so the longer $T_{1 \mathrm{pH}}$ relaxation times were not measured. The magnetization buildup was fit by a single exponential function where the time constant was set equal to $\tau_{\mathrm{cp}}$, the crosspolarization relaxation time. The shapes of the resonances corresponding to the $T$ and $Q$ silicons were independent of time for $\mathrm{cp}$ times ranging from 7 to $15 \mathrm{~ms}$. The long plateau region exhibited by the signal intensities, coupled with a constant spectral shape for each silicon species gave us confidence that the spectrum components for the $T$ and $Q$ silicon species were semiquantitative.

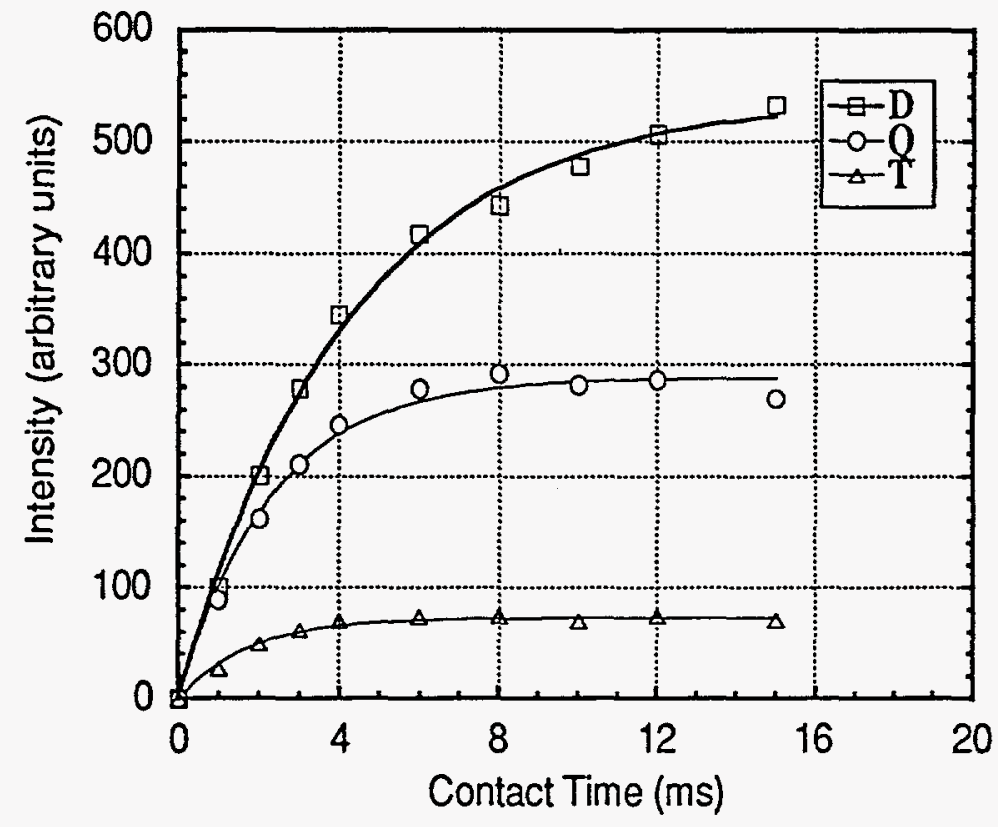

Fig 2. The magnetization buildup of the various silicon species as a function of crosspolarization time.

Deconvolution of the $Q$ resonances showed that the extents of reaction of these silicons ranged from 86 to $92 \%$. These values are somewhat higher than observed for acid-catalyzed TEOS sol-gels. We attribute the greater extent of reaction of TEOS to its mobility when dispersed in the elastomeric matrix. The $\mathrm{T}$ silicons begin the reaction as $\mathrm{T}^{2}$ silicons and condense to form $\mathrm{T}^{3}$ silicons. The extents of reaction of the $\mathrm{T}$ silicons are approximately $65 \%$ for the two $10 / 1$ materials. The lower extent of reaction of the $T$ silicons is probably due to the networking which they experience before the reaction formally begins.

Equilibrium swelling measurements of the elastomers in heptane were used to determine the soluble fraction and to measure the average molecular weight between crosslinks. The results are shown in Table 2. The soluble fraction for elastomers prepared using TEOS was generally higher than the soluble fraction for TEOS-PH elastomers. This is likely due to the fact, that for the hydrolyzate, more of the tetrafunctional silane molecules are locked into the structure with a single condensation reaction. An increase in the soluble fraction was also found for elastomers prepared with decreasing amounts of functionality on the backbone. Fewer reactive sites on the backbone result in fewer attachment sites for nucleation and growth of silica, thereby increasing the number of unattached TEOS derivatives. The molecular weight between crosslinks $\left(\mathrm{M}_{\mathrm{C}}\right)$ 
follows the expected trend with the distance between crosslinks increasing as the distance between functionality on the matrix polymer backbone increases.

Table 2. Soluble fraction, cross-link density, and average molecular weight between cross-links $\left(\mathrm{M}_{\mathrm{C}}\right)$.

\begin{tabular}{|l|l|c|c|c|}
\hline \multicolumn{1}{|c|}{ Elastomer } & Silica Precursor & Soluble Fraction & $\mathrm{M}_{\mathcal{C}}$ & $\begin{array}{c}\text { Cross-link } \\
\text { Density }\end{array}$ \\
\hline MDTOMeM 10/1 & TEOS & 12.5 & 1746 & $3.45 \mathrm{E}+20$ \\
MDTOMeM 10/1 & TEOS-PH & 11.5 & 1893 & $3.18 \mathrm{E}+20$ \\
MDTOMeM 20/1 & TEOS & 14.5 & 3187 & $1.89 \mathrm{E}+20$ \\
MDTOMeM 20/1 & TEOS-PH & 15.8 & 4246 & $1.42 \mathrm{E}+20$ \\
MDTOMeM 50/1 & TEOS & 27.4 & 12841 & $4.69 \mathrm{E}+19$ \\
MDTOMeM 50/1 & TEOS-PH & 23.8 & 11000 & $5.47 \mathrm{E}+19$ \\
\hline
\end{tabular}

The extent to which the various phases are physically coupled can be probed by examining the crosspolarization times of each type of silicon. These times are shown in Fig 3. The crosspolarization times of the $\mathrm{T}$ and $\mathrm{Q}$ silicons are similar to each other indicating that these two phases have similar mobilities. The crosspolarization times of the $D$ backbone silicons are considerable longer than those of either the $\mathrm{T}$ or $\mathrm{Q}$ silicons demonstrating that on the average, these silicons possess greater mobilities. F. Babonneau has reported that the resonance of the D silicons in a material prepared from PDMS and TEOS consists of both a broad and a narrow component [3]. The broad component was associated with the silicons closely coupled to the silica phase. We observe similar behavior for these materials. For short cross-polarization times, the broad component is accentuated relative to the narrow component indicating that these backbone silicons have lower mobilities than the silicons associated with the narrow component.

\section{CONCLUSIONS}

Approximately $65 \%$ of the reactive groups incorporated into the backbone of the PDMS chain were found to have undergone reaction. The concentration of $T$ and $Q$ silicons in the 10/1 formulation are comparable, while the number of $T$ silicons is substantially less than the number of $\mathrm{Q}$ silicons for the 20/1 and 50/1 formulations. Thus, on a statistical basis we expect that a significant number of chemical bonds are formed between the T silicons in the PDMS chain and the $\mathrm{Q}$ silicons in the silica particle. These expectations were confirmed by a decrease in the solubility fraction and an increase in the crosslink density for materials prepared with a high fraction of reactive silicons in the PDMS chain. Cross-polarization relaxation times show that the $T$ silicons in the PDMS chain are also physically coupled to the silica filler particles. We expect that the intimate chemical and physical bonding of the elastomeric and filler phases of these materials will be reflected in their mechanical properties. 


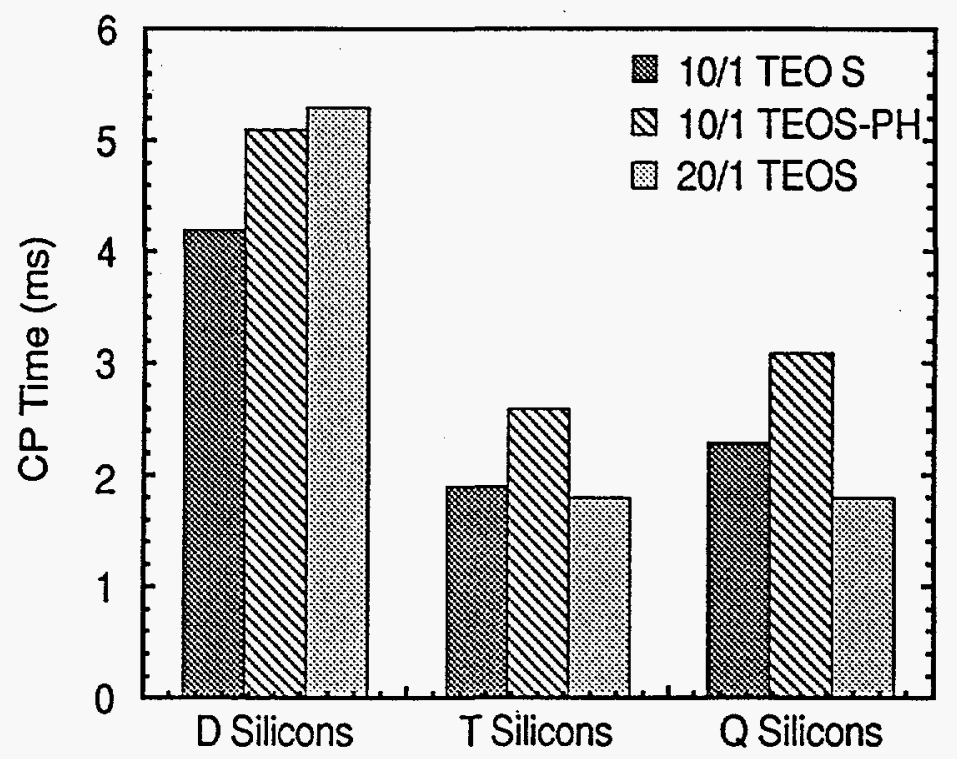

Fig 3. Comparison of cross-polarization relaxation times for the $D, T$ and Q siliconspecies for selected materials.

\section{REFERENCES}

1. For a review of hybrid nanocomposite technologies, see Hybrid Organic-Inorganic Composites. J. E. Mark, C. Y-C Lee, P. A. Bianconi, Eds., ACS Symposium Series 585, American Chemical Society: Washington, D. C. (1995).

2. a. B. M. Novak, Adv. Mater. 5, 422 (1993). b. H. Schmidt in Chemical Processing of Advanced Materials; L. L. Hench, J. K. West, eds., John Wiley \& Sons:- New York, NY, p. 727 (1992). c. J. E. Mark, Chemtech 19, 230 (1989). d. G. L. Wilkes, "Ceramers: Hybrid Inorganic/Organic Networks." in The Polymeric Materials Encyclopedia: Synthesis, Properties and Applications, in press.

3. F. Babonneau, New J. Chem. 18, 1065 (1994).

4. S. Prabakar, R. A. Assink, N. K. Raman and C. J. Brinker, Mat. Res. Symp. Proc. 346, 979 (1994).

5. P. J. Flory, Macromolecules 12, 119 (1979).

\section{DISCLAIMER}

This report was prepared as an account of work sponsored by an agency of the United States Government. Neither the United States Government nor any agency thereof, nor any of their employees, makes any warranty, express or implied, or assumes any legal liability or responsibility for the accuracy, completeness, or usefulness of any information, apparatus, product, or process disclosed, or represents that its use would not infringe privately owned rights. Reference herein to any specific commercial product, process, or service by trade name, trademark, manufacturer, or otherwise does not necessarily constitute or imply its endorsement, recommendation, or favoring by the United States Government or any agency thereof. The views and opinions of authors expressed herein do not necessarily state or reflect those of the United States Government or any agency thereof. 